\title{
Plasmablastic lymphoma with MYC translocation: evidence for a common pathway in the generation of plasmablastic features
}

\author{
Lekidelu Taddesse-Heath ${ }^{1}$, Aurelia Meloni-Ehrig ${ }^{2}$, Jay Scheerle ${ }^{2}$, JoAnn C Kelly ${ }^{2}$ \\ and Elaine S Jaffe ${ }^{3}$ \\ ${ }^{1}$ Department of Pathology, Howard University Hospital, Washington, DC, USA; ${ }^{2}$ Cytogenetics Laboratory, \\ Quest Diagnostics Nichols Institute, Chantilly, VA, USA and ${ }^{3}$ Department of Pathology, National Cancer \\ Institute, National Institutes of Health, Bethesda, MD, USA
}

\begin{abstract}
Plasmablastic lymphoma, which is considered a subtype of diffuse large B-cell lymphoma, shares many similar morphological and immunophenotypic features with plasmablastic transformation of plasma cell myeloma. In the setting of human immunodeficiency virus (HIV) infection, both types of neoplasms can be associated with Epstein-Barr virus (EBV), thus making their distinction challenging. Moreover, the biological relationship between these entities remains unclear. We report four unique cases of plasmablastic lymphoma occurring in the setting of HIV infection that had overlapping clinical and genetic features with plasma cell myeloma. We reviewed the clinical, morphological, and cytogenetic findings and performed immunohistochemistry, in situ hybridization for EBV, chromosome analysis, and fluorescent in situ hybridization (FISH) using the MYC breakapart rearrangement probe. All patients were males with a median age of 45 years. In addition to extra-nodal disease, plasmablastic morphology, and phenotype typical of plasmablastic lymphoma, three of the four cases also showed clinical findings overlapping with plasma cell myeloma, that is, monoclonal serum immunoglobulin and lytic bone lesions. Furthermore, these cases showed complex cytogenetic changes that are more commonly observed in plasma cell myeloma. A unique feature was the presence of $M Y C(8 q 24.1)$ rearrangement confirmed by FISH in all four cases. MYC translocation has been associated with tumor progression in multiple myeloma but has only rarely been previously reported in plasmablastic lymphoma. These cases show a clinical and biological relationship between plasmablastic lymphoma and the plasmablastic variant of plasma cell myeloma. Dysregulation of $M Y C$ may be a common genetic mechanism that imparts plasmablastic morphology and aggressive clinical course to B-cell neoplasms at a later stage of differentiation.

Modern Pathology (2010) 23, 991-999; doi:10.1038/modpathol.2010.72; published online 26 March 2010
\end{abstract}

Keywords: plasmablastic lymphoma; $M Y C$ translocation; plasma cell myeloma

Plasmablastic lymphoma was first described as an aggressive lymphoma presenting in the oral cavity of patients infected with the human immunodeficiency virus (HIV). ${ }^{1}$ It has since been shown to occur in other, mainly extra-nodal, often mucosalassociated sites such as the skin, soft tissue, and gastrointestinal tract. ${ }^{2-5}$ The tumor is composed of large cells with a high proliferative index showing

Correspondence: Dr L Taddesse-Heath, MD, Department of Pathology, Howard University Hospital, 2041 Georgia Avenue, Washington, DC 20060, USA.

E-mail: ltaddesse-heath@howard.edu

Received 12 October 2009; revised 31 December 2009; accepted 3 January 2010; published online 26 March 2010 morphological and phenotypic evidence of plasmacytic differentiation, and hence the designation as plasmablastic lymphoma. Plasmablastic morphology, extra-medullary localization, and a plasma cell immunophenotype can also be observed in aggressive plasma cell myelomas. ${ }^{6,7}$ The distinction between plasmablastic lymphoma and the anaplastic or plasmablastic form of myeloma is based largely on clinical presentation and presence of EpsteinBarr virus (EBV). Plasmablastic lymphoma has a high association with EBV and is thought to lack the hallmark clinicopathological characteristics of plasma cell myeloma, that is, monoclonal paraproteinemia and lytic bone lesions. ${ }^{4}$ We report four cases of plasmablastic lymphoma, three of which 
showed clinical and genetic features, in addition to morphology and phenotype that overlapped with plasma cell myeloma, underscoring the biological relationship between these neoplasms. Moreover, all four cases showed rearrangements of the $M Y C$ gene (v-myc myelocytomatosis viral oncogene homolog (avian)).

\section{Materials and methods}

The cases were obtained from the files of Howard University Hospital, Washington, DC.

A total of six cases of HIV-associated plasmablastic lymphoma diagnosed from 2002 to 2008 were reviewed. The four cases in this report were selected from among the six cases on the basis of unusual clinical features and $M Y C$ translocation. The H\&E and Wright-Giemsa stained slides were reviewed. Immunohistochemical studies were performed on formalin-fixed paraffin-embedded tissue using an automated immunostainer (Ventana Medical Systems, Tucson, AZ, USA) with antibodies to CD20, CD79a, CD3, CD 56, CD10, Ki-67, HHV8, ALK-1, and cyclin D1 (Ventana Medical Systems), CD38, CD138, $\kappa, \lambda$ (DAKO, Carpenteria, CA, USA) according to the manufacturer's instructions. In situ hybridization studies for EBV early RNA (EBER-1) were performed on formalin-fixed paraffin-embedded tissue sections using a Ventana (Ventana Medical Systems) in situ hybridization kit according to the manufacturer's instructions. Flow cytometry studies were performed as part of the clinical workup of the cases. The medical records were reviewed for clinical presentation, staging, laboratory data, radiological studies, treatment, and outcome.

\section{Cytogenetics}

\section{Chromosome analysis}

Cytogenetic studies were performed as part of the clinical workup on three of the six patients. The samples (either bone marrow aspirate or pleural effusion) were processed using standard cytogenetic techniques. In brief, cultures were set up in RPMI1640 medium enriched with $20 \%$ fetal calf serum, giant cell tumor-conditioned medium, L-glutamine, and antibiotics (penicillin and streptomycin). The unstimulated cultures were incubated for 24 and $48 \mathrm{~h}$, whereas the mitogen-stimulated cultures (interleukin 4 (IL-4)) were incubated for $96 \mathrm{~h}$ in a $37^{\circ} \mathrm{C}$ humidified environment with $5 \% \mathrm{CO}_{2}$ until harvest. Before harvest, the cultures were treated with colcemid $(25 \mu \mathrm{l})$ for $16-18 \mathrm{~h}$. After the colcemid treatment, the cells obtained from both cultures were exposed to hypotonic solution $(0.075 \mathrm{~mol} / \mathrm{l}$ $\mathrm{KCl}$ ), fixed with methanol/acetic acid (3:1), spread onto a slide, and G-banded using trypsin and Giemsa stain. The slides were prepared and stained using G-banding (Giemsa-Trypsin-Wright), and 20 metaphases were analyzed from each sample. The cells were imaged and the karyograms were prepared with the Cytovision Computer-Assisted Karyotyping System (Applied Imaging, Santa Clara, CA, USA). These karyograms were described according to the International System for Human Cytogenetics Nomenclature (ISCN 2009). ${ }^{8}$

\section{Fluorescent in situ hybridization (FISH) analysis}

FISH studies were performed in all six patients with the $M Y C$ probe (LSI MYC Dual Color, Break-Apart Rearrangement probe: Abbott Molecular, Des Plaines, IL, USA) to investigate and/or confirm the presence of $M Y C$ gene rearrangement. The FISH procedure was carried out on various tissues, including bone marrow aspirate, pleural effusion as well as formalin-fixed, paraffin-embedded tissue sections, following the manufacturer's guidelines with minor modifications. Furthermore, all samples were also tested for the presence of gains of $5 p$, as well as chromosomes 9 and 15 centromeres (LSI D5S23/D5S721, CEP 9, CEP 15 Multi-color Probe Set; Abbott Molecular), a common finding in myeloma cases with a hyperdiploid chromosome complement. After overnight hybridization and subsequent washing, the slides were analyzed using a Nikon 50i fluorescence microscope (Nikon, Tokyo, Japan). Selected images were captured using an Isis workstation (Metasystems, Watertown, MA, USA).

\section{Results}

\section{Case Histories}

The clinical features of the six patients with plasmablastic lymphoma are summarized in Table 1 . The patients were all males with an age range of 37-59 years (median 48), all of whom were HIV positive. There was no evidence of a previous lymphoproliferative disorder in any of the patients. Four of the six patients (cases 1-4) with plasmablastic lymphoma were positive for MYC translocation. These cases presented with disseminated disease with nodal as well as extra-nodal disease involving the gastrointestinal tract and soft tissue. The lymph node involvement was multifocal, including mesenteric, retroperitoneal, (case 1) cervical, paratracheal (case 2), and inguinal (case 4). The patients with gastrointestinal tract involvement had extensive infiltration of the small bowel and colon wall requiring resection for gastrointestinal obstruction, whereas the patient with a soft tissue mass of the thigh had a $5 \mathrm{~cm}$ ulcerated lesion with massive edema of the leg. Of the four patients with MYC translocation, three had clinical features of plasma cell myeloma, that is, monoclonal serum immunoglobulin and/or lytic lesions, but serum calcium, blood urea nitrogen (BUN), and creatinine were normal. The monoclonal immunoglobulin in all cases constituted $<2 \mathrm{~g}$ per $100 \mathrm{ml}$. In two of these cases, the monoclonal protein was IgG and both of these patients had multiple lytic bone lesions by 
Table 1 Clinical data of patients with plasmablastic lymphoma ${ }^{a}$

\begin{tabular}{|c|c|c|c|c|c|c|}
\hline Case no. & Age/sex & Site & SPEP & Lytic lesion & $B M$ & Outcome \\
\hline 1 & $37 / \mathrm{M}^{\mathrm{b}}$ & $\begin{array}{l}\text { Small intestine, colon, } \\
\text { mesenteric lymph nodes } \\
\text { Testis } \\
\text { Pleural effusion }\end{array}$ & IgG K & Humerus, rib, skull & - & Expired (2 years) \\
\hline 2 & $59 / \mathrm{M}$ & $\begin{array}{l}\text { Small intestine, colon, } \\
\text { generalized lymphadenopathy } \\
\text { Pleural effusion }\end{array}$ & $\operatorname{IgG} \mathrm{K}$ & Thoracic spine & - & Expired (35 days) \\
\hline 3 & $45 / \mathrm{M}^{\mathrm{c}}$ & Soft tissue & IgM K & None & + & Expired (20 days) \\
\hline 4 & $53 / \mathrm{M}$ & $\begin{array}{l}\text { Inguinal lymph node, } \\
\text { soft tissue }\end{array}$ & ND & None & - & Expired (90 days) \\
\hline 5 & $41 / \mathrm{M}$ & Oral cavity & ND & None & ND & NA \\
\hline 6 & $50 / \mathrm{M}$ & Oral cavity & ND & None & - & $\begin{array}{l}\text { Expired } \\
\text { (13 months) }\end{array}$ \\
\hline
\end{tabular}

SPEP, serum protein electrophoresis; BM, bone marrow; ND, not done; NA, not available.

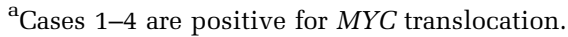

${ }^{\mathrm{b}}$ Lymphoma recurred in the testis 2 years later. The bone marrow was negative initially and at recurrence.

${ }^{\mathrm{C}}$ The bone marrow was infiltrated by identical cells as in the soft tissue.

computed tomography (CT) scans. However, in both patients, despite the extensive mucosal involvement, there was no evidence of bone marrow involvement morphologically and by flow cytometry (performed both initially and at the later recurrence in case 1). The third patient had a monoclonal IgM spike and, in addition to a destructive soft tissue lesion, the bone marrow was diffusely infiltrated by large cells (Figure 1), but there was no evidence of lytic bone lesions. Three of the four $M Y C$ translocation-positive patients did not receive chemotherapy, either because of the patients' clinical condition or refusal of treatment. In these patients, the median survival was 48 days. One of the patients (case 1) was treated with a myeloma regimen (vincristine, adriamycin, and dexamethasone) with improvement in the gastrointestinal tract symptoms. The treatment decision was based on the clinicopathological presentation and marked evidence of plasmacytic differentiation in the tumor cells. The patient responded but relapsed 2 years later with plasmablastic lymphoma in the testis and pleural cavities and expired shortly after. The remaining two $M Y C$ translocation-negative cases (cases 5 and 6) presented with disease limited to the oral cavity with no evidence of lytic lesions. One of these patients received chemotherapy (etoposide, vincristine, doxorubicin, cyclophosphamide, and prednisone (EPOCH)) but developed disseminated disease and died 13 months after initial diagnosis. The second patient was lost to follow-up.

\section{Morphology}

Histologically, all four $M Y C$ translocation-positive cases had extensive infiltration of involved sites by a diffuse proliferation of large cells showing plasmablastic or immunoblastic morphology, that is, abundant basophilic cytoplasm and eccentric nuclei. In some of the cases, there was a starry sky pattern, high mitotic rate, and numerous apoptotic bodies. A variable number of cells that showed morphological features of mature plasma cells, that is, smaller size, clumped chromatin, and paranuclear hofs, were present. The number of the more mature plasma cells ranged from minimal to moderate in the various cases and was most prominent in the initial gastrointestinal tract tumor of one patient (case 1). The tumor in the latter case was most consistent with plasmablastic lymphoma with plasmacytic differentiation, whereas the recurrent tumor in the testis of the same patient 2 years later was more monomorphic and high grade, resembling plasmablastic lymphoma of the oral cavity (Figure 2). The tumors in the two MYC translocation-negative plasmablastic lymphoma of the oral cavity were composed of uniform population of large cells.

\section{Immunophenotype}

The immunophenotypic features of all six cases are summarized in Table 2. The tumor cells were positive for the plasma cell markers CD138 and/or CD38 and negative or weakly positive for B-cell markers (CD20 and CD79a) by flow cytometry and/ or immunohistochemistry in all except one case in which there was strong staining with CD20. The latter case was also positive for CD38 and showed strong monotypic cytoplasmic $\kappa$ light chain. Although expression of CD20 is unexpected, other features favored the diagnosis of plasmablastic lymphoma, including plasmablastic morphology, clinical features, strong cytoplasmic immunoglobulin, and expression of CD38. All cases were negative for cyclin D1. The proliferative rate with Ki-67 ranged from $60 \%$ in the tumors that showed a greater number of more mature plasma cells, to nearly $100 \%$ in the more monomorphic tumors composed mostly of large cells. Partial positivity for 

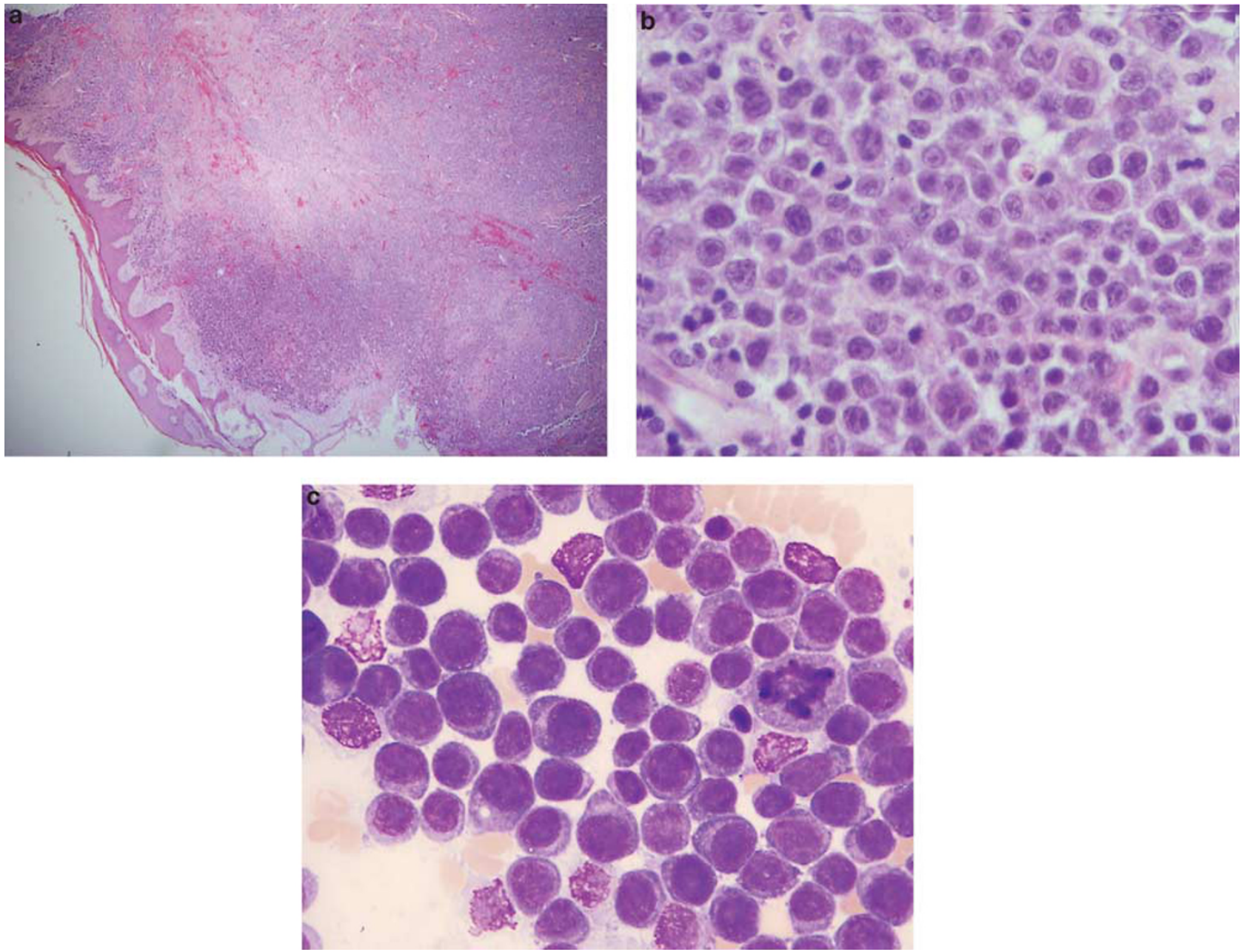

Figure 1 Skin biopsy and bone marrow aspirate from the 45-year-old male patient with a soft tissue thigh mass and bone marrow involvement (case 3). Low-power view of the skin biopsy shows a destructive, lymphoid infiltrate in the dermis (a) (H\&E). The cells are large, with amphophilic cytoplasm and prominent nucleoli (b) (H\&E). The bone marrow was replaced by sheets of large cells with prominent nucleoli. Eccentric nuclei and paranuclear hofs were evident in some of the cells (c) (Wright-Giemsa).

CD56 and CD10 was observed in two cases. In situ hybridization for EBV was positive in four of the six cases, including two of the four MYC translocationpositive plasmablastic lymphoma and both cases of $M Y C$ translocation-negative plasmablastic lymphoma in the oral cavity. HHV8 was negative in all cases.

\section{Cytogenetics and FISH}

The karyotypic and FISH data of the six patients with plasmablastic lymphoma are summarized in Table 3. The chromosome analysis of bone marrow or pleural effusion samples from three of the patients with serum monoclonal spikes and/or lytic bone lesions showed a complex karyotype (Figure 3). The common changes were characterized by rearrangements of chromosomes 1 and/or 6, loss of $13 q$ and $17 p$, and whole or partial gains of chromosomes 3, 5, 7, 9, 11, and/or 15. FISH studies confirmed the presence of gains of $5 p, 9$ as well as 15 centromeres (Figure 3) in the various tissues, including the original as well as subsequent tumors in the patient who had recurrent disease (case 1). In addition, the analysis of the complete karyotype revealed translocations involving the $M Y C$ gene (8q24.1) in all three cases. The translocation partners included the immunoglobulin heavy chain (IGH 14q32) and $\kappa$ (IGK 2p12) or $\lambda$ light chain (IGL 22q11.2) genes. The rearrangement of the $M Y C$ gene was confirmed by FISH (Figure 3) in the three cases noted above, as well as in the fourth patient with plasmablastic lymphoma who had no evidence of a lytic bone lesion (case 4). The latter case also showed gains of $5 p, 9$ as well as 15 centromeres by FISH. Interestingly, in the plasmablastic lymphoma case that showed the most plasmacytic differentiation (case 1), rearrangement of $M Y C$ was detected in $11 \%$ of the tumor cells in the initial gastrointestinal tract lesion, whereas the recurrent, monomorphic high-grade tumor in the testis and pleural cavity 

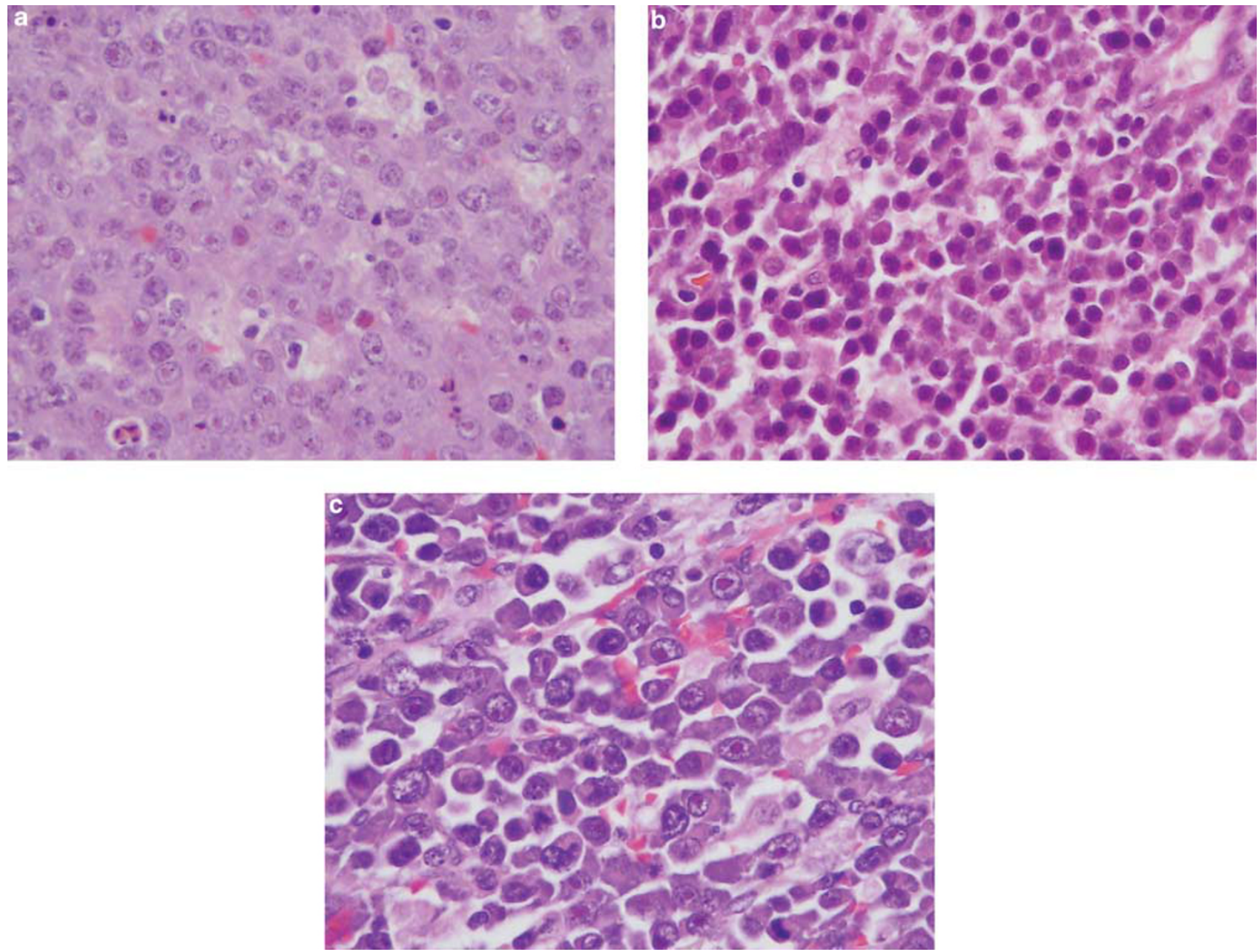

Figure 2 Small intestine and testis from case 1. The intestinal mucosa was extensively infiltrated by lymphoid cells that were large with prominent nucleoli (a) (H\&E). The tumor also had areas of marked plasmacytic differentiation with numerous mature plasma cells (b) (H\&E). The tumor in the testis was high grade with some evidence of plasmacytic differentiation (c) (H\&E).

Table 2 Immunophenotypic features of patients with plasmablastic lymphoma

\begin{tabular}{|c|c|c|c|c|c|c|c|c|c|}
\hline & \multicolumn{3}{|c|}{ Case 1} & \multicolumn{2}{|c|}{ Case 2} & \multirow{2}{*}{$\begin{array}{c}\text { Case } 3 \\
\\
\text { Soft } \\
\text { tissue }\end{array}$} & \multirow{2}{*}{$\begin{array}{c}\text { Case } 4 \\
\\
\text { Inguinal } \\
\text { lymph node }\end{array}$} & \multirow{2}{*}{$\begin{array}{c}\text { Case } 5 \\
\text { Oral } \\
\text { cavity }\end{array}$} & \multirow{2}{*}{$\begin{array}{c}\text { Case } 6 \\
\text { Oral } \\
\text { Cavity }\end{array}$} \\
\hline & $\begin{array}{c}\text { Small } \\
\text { intestine }\end{array}$ & Testis & $\begin{array}{l}\text { Pleural } \\
\text { effusion }\end{array}$ & $\begin{array}{c}\text { Small } \\
\text { intestine }\end{array}$ & $\begin{array}{l}\text { Pleural } \\
\text { effusion }\end{array}$ & & & & \\
\hline CD138 & + & + & + & - & - & + & + & + & + \\
\hline CD38 & + & + & + & + & + & + & + & + & + \\
\hline CD20 & - & - & - & + & + & - & - & - & - \\
\hline CD79A & - & - & - & + & + & - & \pm & - & - \\
\hline Карра & + & + & + & + & + & + & - & $\mathrm{NC}$ & + \\
\hline Lambda & - & - & - & - & - & - & + & NC & - \\
\hline CD56 & + & + & + & - & - & + & - & - & - \\
\hline CD10 & + & + & + & - & - & + & - & - & - \\
\hline Cyclin D-1 & - & - & - & - & - & - & - & - & - \\
\hline ALK & - & - & - & - & - & - & - & - & - \\
\hline HHV-8 & - & - & - & - & - & - & - & - & - \\
\hline Ki-67 & $60 \%$ & $80 \%$ & $80-90 \%$ & $80-90 \%$ & $80-90 \%$ & $100 \%$ & $90 \%$ & $90 \%$ & $90 \%$ \\
\hline EBER & + & + & + & - & - & - & + & + & + \\
\hline
\end{tabular}

EBER, Epstein-Barr virus early RNA; NC, non-contributory.

showed MYC rearrangement in 89 and $94 \%$, respectively, suggesting a $M Y C$-driven tumor progression. FISH for MYC rearrangement and gains of chromo- somes 5, 9, and 15 were all negative in the two patients with plasmablastic lymphoma of the oral cavity. 
Table 3 Karyotype and FISH data of patients with plasmablastic lymphoma

\begin{tabular}{|c|c|c|c|}
\hline Case no. & Site & Karyotype & FISH \\
\hline \multirow[t]{5}{*}{1} & Small intestine & ND & $\begin{array}{l}M Y C+(11 \%) \text { gain of } 5 p, 9 \text { cen, and } 15 \\
\text { cen }(13 \%)\end{array}$ \\
\hline & Bone marrow & $46, X Y$ & ND \\
\hline & Testis & No growth & $\begin{array}{l}M Y C+(89 \%) \text { gain of } 5 p, 9 \text { cen, and } 15 \\
\text { cen }(74 \%)\end{array}$ \\
\hline & Repeat bone marrow & $46, X Y$ & ND \\
\hline & Pleural effusion & $\begin{array}{l}83 \sim 85<3 \mathrm{n}>, \mathrm{XX},-\mathrm{Y},+1, \operatorname{der}(1) \mathrm{t}(1 ; 1)(\mathrm{p} 32 ; \mathrm{q} 25),+2,+3, \\
+4,+6, \operatorname{del}(6)(\mathrm{q} 25) \mathrm{x} 2,+7,+7, \mathrm{t}(8 ; 14) \\
\text { (q24.1;q32)x2,+10,+12,add(13)(q34), } \\
+16, \mathrm{psu} \operatorname{dic}(16 ; 1)(\mathrm{q} 12 ; \mathrm{p} 13) \\
+17,+18,+19,+20,+22,+\operatorname{mar}[\mathrm{cp} 20]\end{array}$ & $\begin{array}{l}M Y C+(94 \%) \text { gain of } 5 p, 9 \text { cen, and } 15 \\
\text { cen }(71 \%)\end{array}$ \\
\hline \multirow[t]{3}{*}{2} & Small intestine & ND & $M Y C+(90 \%)$ gain of $5 p,(73 \%)$ \\
\hline & Bone marrow & $46, \mathrm{XY}$ & ND \\
\hline & Pleural effusion & $\begin{array}{l}47 \sim 49, \mathrm{x},+\mathrm{x},-\mathrm{y}, \operatorname{der}(1) \mathrm{t}(1 ; 4)(\mathrm{q} 21 ; \mathrm{p} 12),+3, \operatorname{del}(3) \mathrm{q}(13.2 \mathrm{q} 23) \\
\mathrm{x} 2,+5,+6, \operatorname{der}(6) \mathrm{psu} \operatorname{dic}(6 ; 1)(\mathrm{p} 25 ; \mathrm{p} 36.3) \\
\text { ins }(6 ; ?)(\mathrm{p} 25 ?), \mathrm{t}(7 ; 10)(\mathrm{q} 22 ; \mathrm{q} 22), \mathrm{t}(8 ; 22) \\
(\mathrm{q} 24.1 ; \mathrm{q} 11.2), \text { add11 (q23),-13,-20[cp20] }\end{array}$ & $M Y C+(91 \%)$ gain of $5 p(69 \%)$ \\
\hline \multirow[t]{2}{*}{3} & Soft tissue & ND & $\begin{array}{l}\text { MYC+ }(87 \%) \text { gain of } 5 p \text {, and } 15 \text { cen } \\
(68 \%)\end{array}$ \\
\hline & Bone marrow & $\begin{array}{l}\text { 46,X,-Y,t(2;8)(p12;q24.1),-4,der(6)t(5;6)(p12;q25),+7,+15, } \\
\operatorname{der}(15 ; 17)(q 10 ; q 10),+20[6] / 46, X Y[14]\end{array}$ & $\begin{array}{l}M Y C+(55 \%) \text { gain of } 5 p \text {, and } 15 \text { cen } \\
(39 \%)\end{array}$ \\
\hline 4 & $\begin{array}{l}\text { Inguinal lymph node, } \\
\text { abdominal } \\
\text { soft tissue mass }\end{array}$ & ND & $\begin{array}{l}M Y C+(35 \%) \text { gain of } 5 p \text {, and } 15 \text { cen } \\
(14 \%)\end{array}$ \\
\hline 5 & Oral cavity & ND & $\begin{array}{l}M Y C \text { negative gain of } 5 p \text {, and } 15 \text { cen } \\
\text { negative }\end{array}$ \\
\hline 6 & Oral cavity & ND & $\begin{array}{l}\text { MYC negative gain of } 5 p \text {, and } 15 \text { cen } \\
\text { negative }\end{array}$ \\
\hline
\end{tabular}

ND, not done; cen, centromere.

\section{Discussion}

We report four unique cases that provide evidence that plasmablastic transformation is highly associated with $M Y C$ translocation and that this finding can be observed in both de novo plasmablastic lymphoma and in the plasmablastic transformation of a more low-grade plasma cell neoplasm, including plasma cell myeloma. These cases are additional evidence that MYC translocation, originally described in Burkitt's lymphoma, may be observed in other lymphomas as well. There have been few previous reports noting the presence of $M Y C$ translocation in plasma cell myeloma, a finding that has been associated with tumor progression to highgrade morphology and an aggressive clinical course $^{9-12}$ Previously, only rare case reports in the literature suggested an association of plasmablastic lymphoma with $M Y C$ translocation, all of which involved the $I G H$ gene as the translocation partner. ${ }^{13-16}$ A recent meeting report from Balague et $a l^{17}$ showed the presence of $M Y C$ rearrangement in 39\% of 28 cases of plasmablastic lymphoma. Our cases are unique in that they had features of both plasmablastic lymphoma and plasma cell myeloma, suggesting a closer relationship between these neoplasms than previously thought. Notably, the cytogenetic changes were similar to those observed in plasma cell myeloma, particularly, the rearrange- ments of chromosome 1 , deletions of $13 q$ and $17 p$, and the simultaneous gains of the odd-numbered chromosomes. Clinical features were overlapping as well. These findings suggest a common histogenesis for both plasmablastic lymphoma and the plasmablastic variant of plasma cell myeloma and provide further evidence linking these two tumors with morphological and immunophenotypic similarities. Moreover, $M Y C$ translocation, observed in all four of our cases, seems to be a common link in tumors showing plasmablastic morphology, with varying clinicopathological manifestations. EBV, which is closely linked to plasmablastic lymphoma, also has a role in producing the plasmablastic phenotype in plasma cell myeloma and was positive in two of the four MYC translocation-positive cases. EBV has been reported to be positive in some cases of plasma cell myeloma with anaplastic or plasmablastic features, often encountered in the setting of immunodeficiency. However, EBV is only rarely associated with plasma cell myeloma and the few cases that have been reported occurred in the setting of multiple myeloma or plasmacytoma, in contrast to the de novo presentation as high-grade aggressive lesion characteristic of plasmablastic lymphoma. ${ }^{6,18}$

The relationship between plasmablastic lymphoma and plasmablastic transformation of plasma cell neoplasms was highlighted in a study by Colomo et $a l^{6}{ }^{6}$ in which plasmablastic lymphomas with 
a

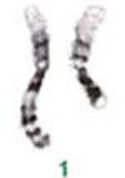

88

है

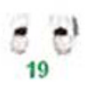

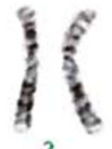

2
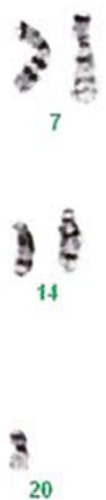
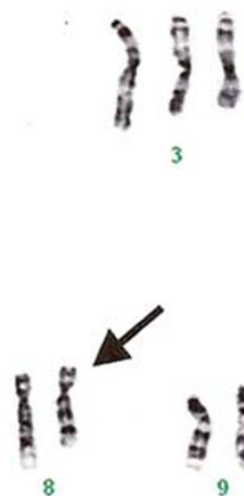

$\frac{\pi}{15}$

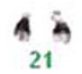

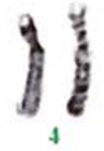

$\frac{8}{3}{ }_{5}^{8} \frac{8}{8}$
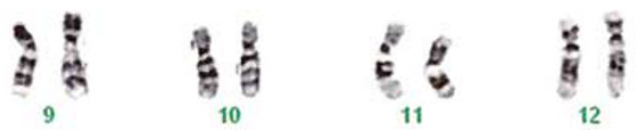

18
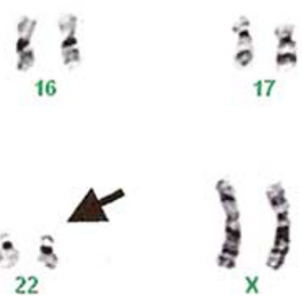

b

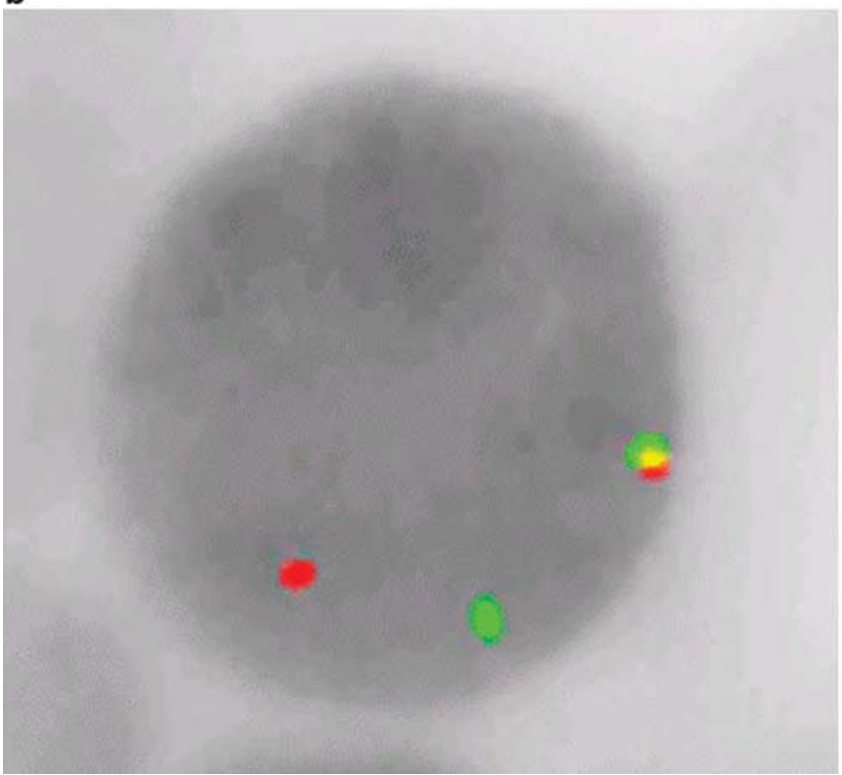

c

Figure 3 G-banded karyogram and interphase FISH from two patients with a plasmablastic lymphoma. The pleural effusion karyotype (case 2) was complex. A translocation between chromosomes 8 and 22, (t(8;22)(q24.1;q11.2)) (arrows), and rearrangements of chromosome 1, loss of chromosome 13, and gain of chromosomes 3 and 5 were detected (a). Interphase FISH revealed one fusion (intact $M Y C$ ), one red $\left(5^{\prime} M Y C\right.$ ), and one green $\left(3^{\prime} M Y C\right)$ signals confirming the rearrangement of $M Y C$ (b). The small intestine and testis (case 1) showed gain of one copy of 5 p (green signal), as well as gains of chromosomes 9 (aqua signal) and 15 (red signal) centromeres.

plasmacytic differentiation were found to be morphologically similar to extra-medullary plasmablastic tumors arising in the setting of a preexisting or concurrent plasma cell neoplasm. Moreover, Vega et $a l^{7}$ provided evidence that plasmablastic lymphomas and plasmablastic plasma cell myelomas share many common immunophenotypic features, includ- ing a high proliferative rate and expression of CD56 and CD10. The latter two markers, which are more often associated with plasma cell neoplasms, were positive in more than half of plasmablastic lymphomas. ${ }^{7}$ Our cases confirm this observation with two of the four cases of plasmablastic lymphoma showing positivity for CD56 and CD10. Owing to the close 
morphological and phenotypic similarities, distinguishing plasmablastic lymphoma from plasmablastic plasma cell myeloma is based on additional clinical features and association with EBV. Thus, high-grade lymphomas with plasmablastic morphology, occurring in immunocompromised patients, localized primarily in extra-medullary sites that are positive for EBV would be designated as plasmablastic lymphoma. In contrast, extra-medullary plasmablastic transformation of plasma cell myeloma occurs in patients with pre-existing or concurrent clinical evidence of multiple myeloma, that is, paraproteinemia, lytic lesions, and proliferation of plasma cells in the bone marrow, peripheral blood, or extra-medullary sites, most commonly the liver and spleen. ${ }^{6}$

Our cases further blur the line between plasmablastic lymphoma and plasmablastic transformation of plasma cell myeloma. Monoclonal serum immunoglobulin spikes were observed in three patients, two of whom had lytic bone lesions. Yet, all patients had normal serum calcium, BUN, and creatinine and had extensive disease outside the marrow in sites often involved by plasmablastic lymphoma. Moreover, in all four cases, despite extensive extranodal and nodal disease, the patients did not have hepatosplenomegaly or peripheral blood involvement and bone marrow infiltration was observed in only one case. Similar overlapping features have also been noted in rare reports ${ }^{19}$ and bone marrow involvement can be observed in plasmablastic lymphoma. ${ }^{6,14,15,19,20}$ Furthermore, plasma cell tumors are reported to have an increased incidence in HIV-positive patients, in which they occur in younger patients, present in unusual sites, show a plasmablastic morphology, are often EBV positive, and show an aggressive clinical course with poor prognosis. ${ }^{21-25}$ Although there is a high association of plasmablastic lymphoma with immunodeficiency $(94 \%)$ and EBV positivity (74\%), not all cases are EBV positive. ${ }^{26}$ In the absence of a previous or concurrent well-differentiated plasma cell neoplasm, high-grade lymphomas with plasmablastic features occurring in HIV-positive patients, particularly when associated with paraproteinemia and bone lesions, are difficult to distinguish from plasma cell myeloma with transformation. The designation of these neoplasms as plasmablastic lymphoma, rather than plasma cell myeloma, is based on de novo presentation as aggressive tumors with plasmablastic morphology, predominant extramedullary, often mucosal involvement, and association with HIV and EBV. Plasma cell myelomas rarely present de novo as high-grade lesions and the association with EBV and HIV is quite rare. Nevertheless, the distinction between these neoplasms may be arbitrary and whether they represent two separate entities or part of a common pathway is controversial. However, the distinction has important clinical and therapeutic implications. The poor clinical outcome in our cases was similar to those reported in the literature for plasmablastic lymphoma with a mean survival ranging from 6 to 15 months with chemotherapy and/or radiation. ${ }^{26,27}$ Plasmablastic lymphomas are mostly treated with combination chemotherapy used for diffuse large B-cell lymphoma. Only rare reports exist that address the potential use of myeloma regimens in the treatment of plasmablastic lymphoma. In one such report, a patient with extra-nodal plasmablastic lymphoma who also had $t(8 ; 14)$ was treated with Bortezomib and reported to have a good initial response.$^{28}$ It is interesting that one of the patients in our study had a relatively longer survival and an initial response to a myeloma-based therapy.

Our cases show that, in addition to the shared clinical and immunophenotypic features, there is a genetic overlap between plasmablastic lymphoma and plasma cell myeloma and that these two neoplasms may be different manifestations of malignancies with a common derivation from $\mathrm{B}$ cells at a later stage of B-cell maturation. It is therefore likely that dysregulation of $M Y C$ may be a common genetic feature that imparts a plasmablastic morphology and an aggressive clinical course in these tumors. The clinical manifestations may depend on when during the clinical course the plasmablastic transformation takes place.

\section{Acknowledgement}

We thank Massih Abawi for the FISH processing of these samples.

\section{Disclosure/conflict of interest}

The authors declare no conflict of interest.

\section{References}

1 Delecluse HJ, Anagnostopoulos I, Dallenbach F, et al. Plasmablastic lymphomas of the oral cavity: a new entity associated with the human immunodeficiency virus infection. Blood 1997;89:1413-1420.

2 Chetty R, Hlatswayo N, Muc R, et al. Plasmablastic lymphoma in HIV+ patients: an expanding spectrum. Histopathology 2003;42:605-609.

3 Schichman SA, McClure R, Schaefer RF, et al. HIV and plasmablastic lymphoma manifesting in sinus, testicles, and bones: a further expansion of the disease spectrum. Am J Hematol 2004;77:291-295.

4 Dong HY, Scadden DT, de Leval L, et al. Plasmablastic lymphoma in HIV-positive patients: an aggressive Epstein-Barr virus-associated extramedullary plasmacytic neoplasm. Am J Surg Pathol 2005;29:1633-1641.

5 Tavora F, Gonzalez-Cuyar LF, Sun CC, et al. Extra-oral plasmablastic lymphoma: report of a case and review of literature. Hum Pathol 2006;37:1233-1236.

6 Colomo L, Loong F, Rives S, et al. Diffuse large B-cell lymphomas with plasmablastic differentiation represent 
a heterogeneous group of disease entities. Am J Surg Pathol 2004;28:736-747.

7 Vega F, Chang CC, Medeiros LJ, et al. Plasmablastic lymphomas and plasmablastic plasma cell myelomas have nearly identical immunophenotypic profiles. Mod Pathol 2005;18:806-815.

8 Shaffer LG, Slovak ML, Campbell LJ, (eds) ISCN 2009: An International System for Human Cytogenetic Nomenclature. S. Karger AG: Switzerland, 2009.

9 Shou Y, Martelli ML, Gabrea A, et al. Diverse karyotypic abnormalities of the c-myc locus associated with c-myc dysregulation and tumor progression in multiple myeloma. Proc Natl Acad Sci USA 2000;97:228-233.

10 Sawyer JR, Lukacs JL, Thomas EL, et al. Multicolour spectral karyotyping identifies new translocations and a recurring pathway for chromosome loss in multiple myeloma. Br J Haematol 2001;112:167-174.

11 Avet-Loiseau H, Gerson F, Magrangeas F, et al. Rearrangements of the c-myc oncogene are present in $15 \%$ of primary human multiple myeloma tumors. Blood 2001;98:3082-3086.

12 Gabrea A, Martelli ML, Qi Y, et al. Secondary genomic rearrangements involving immunoglobulin or MYC loci show similar prevalences in hyperdiploid and nonhyperdiploid myeloma tumors. Genes Chromosomes Cancer 2008;47:573-590.

13 Dawson MA, Schwarer AP, McLean C, et al. AIDSrelated plasmablastic lymphoma of the oral cavity associated with an IGH/MYC translocation-treatment with autologous stem-cell transplantation in a patient with severe haemophilia-A. Haematologica 2007;92: e11-e12.

14 Yotsumoto $\mathrm{M}$, Ichikawa $\mathrm{N}$, Ueno $\mathrm{M}$, et al. CD20negative cd138-positive leukemic large cell lymphoma with plasmablastic differentiation with an IgH/MYC translocation in an HIV-positive patient. Intern Med 2009;48:559-562.

15 Chuah KL, Ng SB, Poon L, et al. Plasmablastic lymphoma affecting the lung and bone marrow with CD10 expression and $t(8 ; 14)(q 24 ; q 32)$ translocation. Int J Surg Pathol 2009;17:163-166.

16 Yamamoto K, Hamaguchi $\mathrm{H}$, Nagata $\mathrm{K}$, et al. A variant Burkitt-type translocation $(8 ; 22)(\mathrm{q} 24 ; \mathrm{q} 11)$ in multiple myeloma. Report of a new case and review of the literature. Cancer Genet Cytogenet 1998;104:98-103.

17 Balague O VS, Marinez A, Colomo L, et al. Plasmablastic lymphomas (PBL) are genetically characterized by frequent $M Y C$ translocations [abstract]. Mod Pathol 2009;22:255A.

18 Chang ST, Liao YL, Lu CL, et al. Plasmablastic cytomorphologic features in plasma cell neoplasms in immunocompetent patients are significantly associated with EBV. Am J Clin Pathol 2007;128:339-344.

19 Teruya-Feldstein J, Chiao E, Filippa DA, et al. CD20negative large-cell lymphoma with plasmablastic features: a clinically heterogenous spectrum in both HIVpositive and -negative patients. Ann Oncol 2004;15: 1673-1679.

20 Simonitsch-Klupp I, Hauser I, Ott G, et al. Diffuse large B-cell lymphomas with plasmablastic/plasmacytoid features are associated with TP53 deletions and poor clinical outcome. Leukemia 2004;18:146-155.

21 Grulich AE, Li Y, McDonald A, et al. Rates of nonAIDS-defining cancers in people with HIV infection before and after AIDS diagnosis. AIDS 2002;16: 1155-1161.

22 Fiorino AS, Atac B. Paraproteinemia, plasmacytoma, myeloma and HIV infection. Leukemia 1997;11: 2150-2156.

23 Frisch M, Biggar RJ, Engels EA, et al. Association of cancer with AIDS-related immunosuppression in adults. JAMA 2001;285:1736-1745.

24 Kumar S, Kumar D, Schnadig VJ, et al. Plasma cell myeloma in patients who are HIV-positive. Am J Clin Pathol 1994;102:633-639.

25 Salarieh A, Rao C, Gottesman SR, et al. Plasma cell tumors in HIV-positive patients: report of a case and review of the literature. Leuk Lymphoma 2005;46: 1067-1074.

26 Castillo J, Pantanowitz L, Dezube BJ. HIV-associated plasmablastic lymphoma: lessons learned from 112 published cases. Am J Hematol 2008;83:804-809.

27 Rafaniello Raviele P, Pruneri G, Maiorano E. Plasmablastic lymphoma: a review. Oral Dis 2009;15:38-45.

28 Bose P, Thompson C, Gandhi D, et al. AIDS-related plasmablastic lymphoma with dramatic, early response to bortezomib. Eur J Haematol 2009;82:490-492. 